\title{
La traducción de Juarez und Maximilian de Franz Werfel en México*
}

Fecha de recepción: 10 de agosto de 2021

Fecha de aprobación: 04 de octubre de 2021

\section{Resumen}

En este artículo se exponen y analizan las dos traducciones al castellano de la obra Juarez und Maximilian, del escritor austriaco Franz Werfel, publicadas en México. El análisis se realiza desde la semiótica cultural, a partir de la teoría de la comunicación expuesta por Göran Sonesson y el proceso de negociación de Umberto Eco. La complejidad de estas traducciones radica en dos aspectos: primero, se trata de una obra que transitó del alemán al inglés y de ahí al español, pero también del alemán al español; y segundo, la necesidad de tener conocimientos de la historia de México para su comprensión. Como resultado, se logra distinguir entre los discursos de cada uno de los textos meta y el texto base, así como su relación con las características biográficas de los traductores y sus competencias culturales, y la utilización de los textos de llegada.

Palabras clave: alemán, literatura, texto de llegada, texto de partida, traducción.

Citar: Morales, María del Sol. "La traducción de Juarez und Maximilian de Franz Werfel en México". La Palabra, núm. 41, 2021, e13312. (1) https://doi. org/10.19053/01218530.n41.2021.13312

\section{María del Sol Morales Zea}

Doctora en Historiografía, becaria posdoctoral de la Maestría en Literatura Hispanoamericana de la Universidad de Guanajuato.

Universidad de Guanajuato. maria.zea.85@gmail.com (D. https://orcid.org/0000-0002$\underline{4585-7935}$

* Artículo de investigación. Este trabajo es parte del proyecto "Problemas y corolarios de la traducción interlingüística e intersemiótica. El caso de Juarez und Maximilian", financiado por las Estancias Posdoctorales Nacionales Conacyt 2020-2021. 


\title{
The translation in Mexico of Juarez und Maximilian by Franz Werfel
}

\begin{abstract}
This article presents and analyzes the two translations into Spanish of the work published in Mexico Juarez und Maximilian by the Austrian writer Franz Werfel. The analysis is carried out from the cultural semiotics, the communication theory exposed by Göran Sonesson and the negotiation process by Umberto Eco. The complexity of these translations can be found in two aspects: first, it is a work that passed from the German to English and from there to Spanish, but also from German to Spanish; and second, the required knowledge of Mexico's history to achieve its understanding. As a result, it is possible to distinguish between the discourses of each of the target texts and the base text, as well as their relationship with the biographical features of the translators and their cultural competencies, and the usage of the target texts.
\end{abstract}

Keywords: Translation, germany, literature, target text, source text.

\section{A tradução de Juarez und Maximilian de Franz Werfel no México}

\section{Resumo}

No presente artigo expõem-se e analisam-se as duas traduções ao castelhano da obra Juarez und Maximilian, do escritor austríaco Franz Werfel, publicadas no México. A análise é desenvolvida com base na semiótica cultural, a partir da teoria da comunicação de Göran Sonesson e do processo da negociação de Umberto Eco. A complexidade das traduções estudadas está dada por dois aspectos: primeiro, trata-se de uma obra que transitou do alemão para o inglês e daí para o espanhol, mas também do alemão para o espanhol; e, segundo, a necessidade de possuir conhecimentos da história do México para a sua compreensão. Como resultado, distinguem-se os discursos de cada um dos textos alvo e do texto de partida, assim como a sua relação com as características biográficas dos tradutores e as suas competências culturais, e a utilização dos textos de chegada.

Palavras-chave: alemão, literatura, texto de chegada, texto de partida, tradução. 


\section{Introducción}

En medio del reordenamiento mundial que significó el fin de la Gran Guerra, en Austria específicamente los restos del antiguo Imperio Austrohúngaro, el dramaturgo Franz Werfel escribió una obra sobre el Segundo Imperio Mexicano: Juarez und Maximilian, en 1924. El protagonista de la historia es su compatriota, el archiduque de Austria-Hungría, Fernando Maximiliano de Habsburgo; aquel a quien los conservadores mexicanos convencieron de ser Emperador de México. El Segundo Imperio Mexicano es un tema de gran riqueza semiótica, pues su tratamiento refleja frecuentemente simpatías y juicios hacia uno u otro bando. Al mismo tiempo, las distintas interpretaciones de dicho suceso se producen siempre en marcos referenciales distintos, puesto que el gran interés en este episodio histórico se ha mantenido inquebrantable por más de cien años. En este artículo, nos adentraremos en el análisis de las traducciones de la obra de Franz Werfel publicadas en México, tomando este caso como ejemplo de las diferencias que la labor de traducción experimentó durante la primera mitad del siglo xx, décadas previas a su profesionalización. Entendiendo dicha profesionalización como la conjugación de dos elementos clave: una industria editorial robusta y con tradición en las traducciones, y la existencia de traductores que se dedican a la labor de forma continua y sistemática, lo que redunda en una teorización propia sobre la materia.

Primero, el drama de Werfel fue traducido en México por Enrique Jiménez Domínguez, en 1931, bajo el título Juárez y Maximiliano. Durante muchos años esta sería la única versión publicada en el país, contando con una segunda edición de esta misma traducción hacia la década de 1970. Fue hasta inicios del siglo xxi, que se publicó en México una nueva edición, esta vez con la traducción de Elvira Martín y Annie Reney, como parte de la colección Serpiente Emplumada de Factoría Ediciones (en 2002), que reunió títulos históricos sobre México y obras de autores mexicanos canónicos. Sin embargo, la traducción de Martín y Reney no es reciente, pues data de 1946, y fue publicada por primera vez en Argentina. Estas dos traducciones forman el corpus principal del presente estudio.

Si bien se piensa habitualmente en la traducción como un acto de equivalencia, en la que se debe dotar al producto de valores similares a los del original, manteniendo al mismo tiempo "efectos de sentido" similares (Dusi 189), los casos que aquí se tratarán se dan en momentos y lugares distintos, por traductores con diferentes niveles de formación en el área, y al menos en un caso, con un fin distinto a la sola traducción. Por tanto, se advertirán cambios en los textos de llegada que interesan aquí, no por una crítica a la fidelidad del original, sino por lo que revelan respecto al proceso de traducción.

En ese sentido, recuperamos la idea de Umberto Eco, quien remarca que la traducción ocurre "no entre dos lenguajes, sino entre dos culturas" (Eco, Decir casi lo mismo 17). Así lo ha desarrollado en sus estudios de semiótica cultural Göran Sonesson, quien propone un modelo de comunicación que integra las propuestas hechas por las escuelas de Tartu y Praga. Dicho modelo retoma el concepto de concreción para referirse a los lugares de indeterminación presentes en una obra, los cuales el intérprete (traductor) determinará (Sonesson 164-165). En ese espacio es donde tiene lugar el proceso de negociación en la que, tal como la explica Eco, en Decir casi lo mismo, convergen el texto fuente, el autor y la cultura donde se crea, 
pero también el texto de llegada, la cultura receptora, e incluso, la industria editorial (Eco 25). En consecuencia, el presente estudio considerará los aspectos culturales, no sólo en sus diferencias geográficas, sino temporales, como parte central del proceso de traducción, por lo que el conocimiento de la formación y contexto de los traductores formará parte del estudio.

\section{Las obras y sus autores}

Juarez und Maximilian fue publicada en 1924 y pronto esta obra fue montada en varias ciudades de Austria, ya que el prestigio de Franz Werfel (1890-1945) lo permitía. El segundo hijo de una familia judía de Praga había sido educado, no obstante, en el catolicismo hegemónico de la ciudad y del Imperio Austro-Húngaro. Realizó sus estudios en los mejores colegios praguenses, en donde se hizo amigo de importantes escritores de su generación. Muy joven, para decepción de su padre, decidió dedicarse a la escritura y más tarde se instaló en Viena.

El primer libro de Werfel fue una colección de poemas, Der Weltfreund, publicado en 1911, pero pronto incursionó en el drama con la obra de un acto Die Versuchung: Ein Gespräch des Dichters mit dem Erzengel und Luzifer en 1913, mismo año en que publicó su segundo libro de poemas Wir sind. Durante la Primera Guerra Mundial sirvió en el ejército imperial, primero como operador de teléfono y después en el Buró de Prensa Militar. Durante el conflicto publicó una versión de Eurípides y su tercer libro de poemas Einander. Tras la guerra, Werfel publicó un nuevo libro de poesía, Der Gerischtag (1919), y al año siguiente dos dramas, Spiegelmensch: Magische Trilogie y Spielhof: Eine Phantasie, y su primera novela Nicht der Mörder, der Ermordete ist schuldig. A estos le seguirán otros dos dramas: Bocksgesang, en 1921, y Schweiger, en 1922. En seguida publicaría otra colección de poesía, Beschwörungen, y en 1924 publicaría la novela Verdi: Roman der Oper y el drama Juarez und Maximilian con su nueva editorial, Paul Zsolnay.

No es extraña la predilección de Werfel por la creación de obras teatrales, pues estas tenían una larga tradición en Viena. Desde finales del siglo xviii, la ciudad se había convertido en el centro teatral de habla alemana. ${ }^{1}$ No obstante, en las primeras décadas del siglo xx el teatro vienés fue opacado por el de Berlín, que presentaba propuestas innovadoras tales como las de Bertolt Brecht, lo que no impedía que siguiera siendo un entretenimiento muy popular en la ciudad. El teatro austrohúngaro reflejaba en gran medida la decadencia de su imperio, y tras la disolución de Austria-Hungría, resultado de su derrota en la Gran Guerra, el teatro fue resaltado como parte de la identidad austriaca (Pyrah 1), que buscaba sus asideros entre los escombros del Imperio. El estilo y las temáticas del teatro werfeliano fueron, en ese sentido, coincidentes con el ambiente sociocultural, antes que críticos o vanguardistas. Aun así, se le considera un representante del expresionismo en Austria, tanto por su poesía como por sus obras teatrales, en las que siempre resaltaba el drama psicológico de sus protagonistas. ${ }^{2}$ Los

Se considera que esto se debió a las reformas promovidas por el emperador Joseph II, quien decretó la Spektakelfreiheit, que permitía la libre representación de obras con la instalación de teatros fuera de las murallas de la ciudad, y la fundación del Burgtheater, todo en 1776 (Pyrah 1-2).

2 El expresionismo buscaba precisamente la expresión de los sentimientos, sensaciones y motivaciones desde el interior de los propios personajes (Pyrah 52). 
temas bíblicos y la espiritualidad forman parte importante de su obra y esto se refleja incluso en Juarez und Maximilian, en el que la fe católica del archiduque cobra especial importancia.

El público respondió positivamente al montaje de Juarez und Maximilian, que se realizó en el teatro Josefstadt, el 26 de mayo de $1925,{ }^{3}$ bajo la dirección del célebre Max Reinhardt. Existen, además, imágenes de la puesta en escena realizada en la República de Weimar, publicadas en el Berliner Ilustrirte Zeitung, número 18, igualmente en 1925; y noticias de su estreno en Dresde en septiembre de ese mismo año, en donde se auguraba que se presentaría en la temporada de invierno en Berlín, debido a su éxito. ${ }^{4} \mathrm{Al}$ año siguiente, el Theatre Guild de Nueva York patrocinó una primera traducción al inglés realizada por Ruth Langner, misma versión que utilizaron para el montaje de la obra que la compañía estrenó en octubre de $1926 .{ }^{5}$ Ese mismo año Langner realizó, a su vez, la traducción de The Goat Song (Bocksgesang) de Werfel.

El Theatre Guild había sido fundado en 1918 por Lawrence Langner, Theresa Helburn y Armina Marshall, esta última esposa de Langner quien fungió como primera codirectora. ${ }^{6}$ Durante décadas, la compañía se dedicó a la producción de obras teatrales, introduciendo en muchas ocasiones a autores de renombre en Europa, para lo cual contó con Ruth Livingstone Langner como traductora del alemán y el húngaro. Ruth era nuera de Lawrence, pues se había casado con su hermano Herbert Langner. De origen judío y nacida en Nueva York, Ruth trabajó durante la Primera Guerra Mundial como censora de correos debido a su dominio de los idiomas. Durante la Segunda Guerra Mundial, su gusto por el teatro la llevó a participar en el American Theatre Wing Canteen, centro de entretenimiento que recaudaba fondos para la guerra. Entre los autores traducidos por Ruth Langner están: Otto Indig, Ferenc Molnár, Sergei Tretyakov, Stefan Zweig, Franz Werfel, Frank Leonhard y Leo Lania entre otros. ${ }^{7}$

Mientras tanto, en Austria, la misma Editorial Paul Zsolnay realizaría una segunda edición de Juarez und Maximilian en 1927 y una tercera en 1931. Asimismo, entre 1930 y 1931 se preparó una ópera en francés basada en la obra de Werfel: Maximilien. Opéra historique en trois Actes et neuf Tableaux (1931) (Maximiliano. Ópera histórica en tres actos y nueve cuadros) de Darius Milhaud, con libreto de R. S. Hoffman. Esta obra se realizó sobre la traducción de Juarez und Maximilian que del alemán al francés hizo Française d>Armand Lunel.

Ahora bien, 1931 fue también el año en que apareció la primera traducción al español, Juárez y Maximiliano, una traducción realizada por Enrique Jiménez Domínguez (1891-

De acuerdo con el programa del estreno que se conserva en el Theater Museum de Viena. "Juarez und Maximilian”. Web 9 Jul. 2021

4 Reuter, Gabriel. "Franz Werfel's Drama of Maximilian and Mexico". The New York Times, 13 de septiembre de 1925.

5 El programa del estreno señala que la primera función fue presentada el lunes 11 de octubre de 1926, bajo la dirección de Raymond Sovey y Kate Lawson. The Theatre Guild Program. Juarez and Maximilian by Franz Werfel at the Guild Theatre, s/e, 1926.

6 Fowler, Glenn. "Arminda Marshall Is Dead at 96; Co-Founder of the Theater Guild”. The New York Times, 22 de julio de 1991, p. 24

7 "Ruth Langner, "60, Play Translation". The New York Times, 4 de abril de 1959, p. 19. En 1928 realizó una versión de Volpone de Ben Jonson junto con Stefan Zweig y al año siguiente tradujo la obra de Franz Leonhard, Karl and Anna. En 1934, tradujo Races de Ferdinand Buckner y en 1935 realizaría un guión teatral basado en el drama de Otto Indig Torockói menyasszony (1931), escrito en húngaro, The Bride of Torozko en 1935. 
1952), quien también escribió el prólogo de la obra. Esta formó parte de la colección de Traducciones Selectas de la Editorial "La razón” S. A., y fue publicada como libro doble, ya que en la segunda parte del libro se incluyó el ensayo "Juárez una interpretación humana", de José Manuel Puig Casauranc (1888-1939), cuya extensión es similar a la obra teatral. Este último era, asimismo, el fundador de la editorial, médico y político de importancia dentro del régimen posrevolucionario. Puig Casauranc fue, entre otras cosas, escritor, secretario de Educación Pública durante la presidencia de Plutarco Elías Calles (1924-1928), y secretario de Relaciones Exteriores entre 1932 y $1934 .{ }^{8}$

Por su parte, Jiménez Domínguez, de formación abogado, fue un miembro joven de la generación del Ateneo de la Juventud, pues figura en la lista de sus miembros. Esto es fundamental para entender su carrera posterior, ya que los fundadores e integrantes de dicho grupo fueron décadas más tarde $-\mathrm{y}$ junto con los intelectuales españoles refugiados en México-, los encargados de emprender la mayor empresa de traducción sostenida en el país hasta entonces (Pérez Martínez 30). Esta labor se realizaría desde la Secretaría de Educación Pública, el Fondo de Cultura Económica y el Colegio de México, con traductores mexicanos destacados como Alfonso Reyes, Xavier Villaurrutia, el español José Gaos y, más tarde, Octavio Paz (Bastin; Gallego Roca; Pérez Martínez; Vega Cernuda).

Por su parte, Jiménez hizo estudios de posgrado en Inglaterra, se desempeñó como profesor de la Facultad de Filosofía y Letras de la Universidad Nacional Autónoma de México y era miembro fundador, junto con Puig Casauranc, de la Editorial "La razón" S. A. ${ }^{9}$ Poco después, tradujo otras obras teatrales a petición de la Secretaría de Educación Pública, a través de la Sección de Teatro del Departamento de Bellas Artes. ${ }^{10}$ Fuera del género dramático, Jiménez tradujo Fourier, de Félix Armand y René Maublanc, para el Fondo de Cultura Económica en 1940. Todo dentro de la tendencia de los grupos culturales y universitarios que buscaban conectar a los mexicanos con el resto del mundo, algo que era en realidad contrario al nacionalismo imperante en el discurso político de la época.

En su prólogo, de Juárez y Maximiliano, Jiménez resaltó la traducción al inglés que había patrocinado el Theatre Guild, una pista sobre el origen de su propia traducción, la cual realizó precisamente sobre la versión al inglés y no sobre la original en alemán. Esto es decisivo para su traducción, pues, aunque el traductor no lo sabía, el resultado será una versión bastante distinta de la original, como se verá a lo largo de este trabajo. Por otro lado, la finalidad del ensayo de Puig Casauranc, incluido en esta edición, fue servir de complemento a la obra de Werfel, que se caracteriza por la ausencia de Benito Juárez como personaje. Por

8 Se retiró de la política luego de otros encargos como diplomático en Argentina y Brasil, debido a la lealtad hacia Plutarco Elías Calles después del rompimiento entre este y Lázaro Cárdenas. Ingresó en 1934 a la Academia Mexicana de la Lengua "José Manuel Puig Casauranc". Académicos. Academia Mexicana de la Lengua. Web 21 Jul. 2021; "José Manuel Puig Casauranc". Enciclopedia de la literatura en México. Fundación para las Letras Mexicanas. Web 21 Jul. 2021.

9 Posteriormente, en 1933, entraría al servicio diplomático en la Secretaría de Relaciones Exteriores, fue ministro de la Sociedad de Naciones en Ginebra y ministro consejero en Francia. Su carrera continuó como funcionario de la Secretaría del Trabajo (Peredo).

10 "Se han encomendado traducciones de distintas obras teatrales a los señores Javier Villaurrutia, Agustín Lazo, Julio Bracho, Salvador Echavarría, Enrique Jiménez Domínguez, Mario Mariscal, José María Ramos y señora Mariana Frenk, así como al jefe de esta Sección señor Rodolfo Usigli” (Vázquez Vela 385). 
ello, el ensayo ahonda en la personalidad de Juárez a partir de la correspondencia personal que el prócer mantuvo con su yerno Pedro Santacilia, resaltando el lado emotivo del prócer. Se sabe que la traducción de Enrique Jiménez tuvo al menos una reimpresión en México, realizada por la Editora Nacional en 1972; no obstante, en dicha reimpresión no se incluye ya el estudio de Puig.

En 1934, se estrenó en México la película Juárez y Maximiliano, del director Miguel Contreras Torres, basada en la obra de Werfel, muy probablemente de la traducción hecha por Jiménez Domínguez. ${ }^{11}$ Poco después, en 1939, se estrenaría la película Juarez en Hollywood, esta sí es, abiertamente, basada en la obra del praguense y dirigida por William (Wilhelm) Dieterle. Por su parte, hacia finales de 1940, Werfel se encontraba ya instalado en Estados Unidos a donde llegó como parte de la diáspora judía que huía del antisemitismo nacionalsocialista propagado en Europa. Su deceso ocurrió en dicho país unos años más tarde, en 1945.

Tras su muerte, se realizó otra traducción al español de Juarez und Maximilian publicada en 1946 por Emecé Editores, en Buenos Aires, a cargo de Elvira Martín (1906-1997) y Annie Reney. Elvira Martín Rodríguez de Pubul, ${ }^{12}$ originaria de La Coruña, formó parte del exilio español en Argentina (Cagiao Vila 136), después del asesinato de su padre a manos de los franquistas. Durante su estancia en Argentina realizó varias traducciones, posibles gracias a la existencia de una industria editorial sólida, con varios años de experiencia en la traducción, con exponentes que iban desde Bartolomé Mitre hasta Jorge Luis Borges (Bastin 205). En este nicho, la llegada de exiliados españoles que tenían ya una larga tradición en la tarea de traducción, ${ }^{13}$ apuntaló aún más el círculo de traductores de la Argentina (Willson 60). Inclusive, en 1945 se crea en Buenos Aires el primer programa universitario para traductores (Bastin 209; Willson 30), lo que demuestra que la traducción era ya considerada un trabajo que requería conocimientos especializados.

Juárez y Maximiliano fue parte de una serie de dramas austriacos que Anna Lifezis nombre oficial de Annie Reney (1902-1987) — ${ }^{14}$ tradujo al español en colaboración con Martín. Lifezis era austriaca de ascendencia judía, también había emigrado a Argentina para escapar del nazismo. En Buenos Aires, fundó junto con su esposo la editorial International Editor

11 La productora Columbia Pictures negó en su momento toda relación del drama werfeliano y la película que ellos distribuyeron, y en sus créditos aparece como una idea original de Miguel Contreras Torres, su director (Morales Zea 129).

12 Elvira Martín perteneció a una destacada familia gallega, su abuelo materno, José Rodríguez Martínez, fue un famoso doctor y periodista de ideas republicanas. Su padre, Joaquín Martín Martínez, activo republicano, fue asesinado en 1936 por ser parte del Ayuntamiento de La Coruña al ocurrir el golpe de estado franquista. Estuvo casada con el doctor José Pubul Cartelle, cuyo apellido utiliza en algunas publicaciones. Realizó traducciones de los libros de Leo Perutz, Alexander Lernet-Holenia y Arthur Schnitzler en colaboración con Annie Reney; sumado a eso, individualmente, tradujo del inglés Peonia de Pearl S. Buck. No obstante, su trabajo más reconocido es la colección de biografías de Concepción Arenal, Rosalía de Castro y Emilia Pardo Bazán, publicadas bajo el título Tres mujeres gallegas del siglo xix, en 1962. "El ayuntamiento reedita Tres mujeres gallegas del siglo xix", La voz de Galicia, 17 de noviembre de 2008.

13 Sobre esto véase la amplia obra Historia de la traducción en España, editada por Francisco Lafarga y Luis Pegenaute, de la que aquí retomamos los capítulos de Miguel Gallego Roca y Miguel Ángel Vega. Además, el Portal de Historia de la Traducción en España contiene los apartados el "Diccionario histórico de la traducción en España", "Historia de la traducción en España" y "Pensamiento sobre la traducción es España". Esta obra monumental nos permite ver lo prolongado y diverso del trabajo de traducción español, que va del siglo v hasta la actualidad (http://phte.upf.edu/).

14 Nació en Viena con el nombre de Anna Renée Scherman, después de su matrimonio con el doctor Hugo Lifczis adoptó el apellido de su esposo. Al emigrar a Argentina cambió su nombre a Anna Lifezis, pero firmó sus traducciones con el seudónimo de Annie Reney. 
Company ${ }^{15}$ y realizó varias traducciones de dramaturgos austriacos; entre ellos Primavera de otoño de Franz Werfel, así como obras de Leo Perutz, Alexander Lernet-Holenia, Arthur Schnitzler, Bertolt Brecht, entre otros. Jorge Luis Borges escribió el prólogo que acompaña la versión de Juárez y Maximiliano de Emecé Editores, misma editorial que editó y publicó la obra borgiana durante décadas en Argentina. En 2002, Factoría Ediciones recuperó esta traducción y la publicó en México dentro de su colección La Serpiente Emplumada. En esta nueva edición, se reúnen tanto el prólogo de Enrique Jiménez como el de Jorge Luis Borges, pero se eliminó el estudio de Puig.

Como nota aclaratoria, en lo sucesivo, se citará la traducción al español de Martín y Reney por tratarse de la más apegada al texto de partida, exceptuando los casos en los que dicha traducción presente divergencias importantes con la obra original y sea, por tanto, objeto de análisis.

\section{Las pérdidas o la traducción orientada al espectador}

Para iniciar el análisis de los textos meta y, de acuerdo con los aspectos implicados en la negociación, es necesario ahondar en las circunstancias que cada traducción tuvo, pues en ello radica el tipo de traducción que se hizo. Por ello, antes de analizar la versión al español de Jiménez Domínguez es indispensable analizar primero las condiciones de la traducción de Langner, en la que el primero se basó. Como sabemos, Juarez and Maximilian fue una traducción pensada para la representación inmediata en Nueva York; este fue el objetivo utilitario de la traducción, que luego sería publicada como libro y vendida como otra forma de obtener ganancias para la compañía teatral. Esto explica en buena medida las muchas licencias (podríamos decir artísticas), que Langner se tomó en la traducción de la obra. Además, se trata de una traducción no profesional, puesto que no se hace dentro de una editorial propiamente, sino como parte del trabajo de la compañía teatral. La misma carrera posterior de Langner nos confirma que su trabajo se desarrolla más en la adaptación teatral y cinematográfica - traducción intersemiótica o de un medio a otro-, que en la traducción interlingüística propiamente. Aquí se establece una diferencia entre traducción interlingüística, es decir, el traslado de una lengua a otra (Jakobson 233) y la adaptación teatral para la puesta en escena, que implica cambios que el adaptador, o la producción en su conjunto, considera necesarios para el montaje de su propio espectáculo. Veamos los cambios que introdujo Langner en el drama.

Generalmente, cuando se realiza una traducción es posible que ocurran pérdidas, es decir, que alguna parte o fragmento del texto fuente no sea traducido al texto meta. Esto puede ocurrir por diversas razones, algunas de ellas son: la imposibilidad de mantener la idea original en la lengua de llegada, la dificultad de imitar las estructuras lingüísticas de otras lenguas o la inexistencia en la cultura de llegada de los referentes que dan sentido a una oración (Eco, Decir casi lo mismo 120-135). En la versión de Langner existen muchas pérdidas, especial-

15 La editorial abrió después una sucursal en Barcelona, a donde se mudó el matrimonio en 1960. Tras la muerte de su esposo, Anna Lifezis volvió a Viena en donde falleció. Esto se puede consultar en la página de la editorial https://www. internationaleditors.com/es/agencia-literaria/ieco/ 
mente de diálogos eliminados, algunos de ellos podrían ser parte de la adaptación cultural necesaria para una mejor recepción de la obra, es decir, pensando en una traducción orientada a la cultura de llegada. Se puede advertir, por ejemplo, que Langner decidió eliminar todas las referencias intertextuales dentro de la obra, de manera que las menciones de Werfel a Victor Hugo (del cual afirma escribió algo sobre Maximiliano) y Virgilio ${ }^{16}$ fueron eliminadas completamente. Posiblemente, la traductora consideró que la sociedad neoyorkina y específicamente el público que solía asistir a sus funciones, no podría comprender las referencias.

Siguiendo el orden de la obra, la escena inicial en la que se habla de la ciudad de Chihuahua es precisamente una de las que más transformaciones experimentó en la versión de Langner. En el texto de Werfel, el corresponsal de guerra Clark se refiere a Chihuahua como "Nest" (nido), y añade: "Ach, es ist das Ende bewohnter Welt" (Ah, el fin del mundo habitado) (Werfel, Juarez und Maximilian 10). En su traducción, Langner hace decir a Clark "dump" (basurero) para referirse a Chihuahua, y al comparar la pronunciación de Chihuahua como Chicago el corresponsal exclama: "What, this dump? There's nothing like this dump in Chicago" ("¿Qué? ¿Este muladar? No hay nada en Chicago como este agujero") (Werfel, Juarez and Maximilian 2, 14). El cambio semántico es evidente, pues pasa de la descripción de un lugar inhóspito y desconocido (Nest), a la comparación y desprecio (dump o muladar).

Entre las omisiones, son de especial importancia aquellas que evidencian una censura sobre el discurso religioso y el histórico. Más adelante en el drama, se omite un diálogo en el que Maximiliano expresa su rechazo hacia el culto guadalupano de sus súbditos. El catolicismo de Maximiliano queda de manifiesto constantemente a lo largo de la obra y lo lleva a afirmar: "Die Anbetung der Madonna von Guadelup gleicht ja dem heidnischen Astartedienst" (Werfel, Juarez und Maximilian 53). Un comentario que fue eliminado por Langner, aunque Martín y Reney sí lo traducen: "La adoración de Nuestra Señora de Guadalupe casi se asemeja al culto pagano de Astarté" (Werfel, Juárez y Maximiliano 38). Esta pérdida resulta pertinente, aunque involuntaria en la versión de Jiménez. Los motivos culturales saltan a la vista, al tratarse de una de las advocaciones más populares en México, una crítica de este tipo sin duda no habría sido bien recibida ni por los lectores, ni por el público del teatro.

Otra pérdida en el texto de Langner es la que provoca al eliminar los elogios que le hacen a Porfirio Díaz: "Dir sind unsinnige Affairen gelungen, Siege über Bazaine, Trujeque, Ganz, über lauter Kriegsschulkapazitäten. Dabei bist Du Jurist und verstehst von den Feinheiten der Strategie so viel wie vom Sonettendichten" (Werfel, Juarez und Maximilian 93). ${ }^{17}$

Con esto, Werfel quiso remarcar la faceta de Díaz como hombre de letras, puesto que antes de ser general del ejército juarista había estudiado derecho, e incluso, fue maestro de latín (Garner 59-60). Sobre las razones para eliminar el comentario solo se puede pensar en simpatías políticas, pues no es el único momento en el que Langner disminuye la participa-

16 Para convencer a Maximiliano, Pierron le aconseja: "Que su majestad se aferre a la palabra de Virgilio 'Si no puedo conmover los cielos, sacudiré el Aqueronte'. Lo que está en juego es el triunfo final” (Werfel, Juarez and Maximilian 70). "Has tenido éxito en las más irracionales empresas, sobre Bazaine, Trujeque, Ganz, sobre las autoridades de la escuela de guerra. Y, sin embargo, tú eres abogado y comprendes tanto las complejidades de la estrategia como la escritura de los sonetos" (traducción propia). 
ción o el lucimiento de Díaz, a quien Werfel ubica como el hombre más valioso del ejército y del Gobierno republicano, solo después de Juárez.

También se nota la censura de diálogos en las partes en que se habla de los indios. En el texto de Werfel, cuando el corresponsal norteamericano inquiere sobre los indios mexicanos, lo hace afirmando:

¡Dígame buen hombre! Los indios de ustedes no se parecen a nuestros pieles rojas del Norte. Aquí forman la gran masa del pueblo, se mezclan con los blancos, viven en las ciudades y visten como nosotros. ¿Acaso no hay tribus que hayan conservado sus costumbres y su religión? ${ }^{18}$ (Werfel, Juárez y Maximiliano 11)

El tema de los indios en Estados Unidos ha sido siempre controversial, quizá esa fue la razón por la que Langner decidió eliminar este diálogo, en el que se apreciaba una opinión desfavorable sobre los pueblos originarios de América del Norte. Un concejal de Chihuahua es el interlocutor de este diálogo, que ante la pregunta responde:

$¡ O h$, señor! Hay muchos centenares en la Sierra Madre, en la Sierra Leona, en todas las cordilleras; repudian los sacramentos, tiene sus altares, sus magias, sus encantamientos, sus tambores del templo y sus ídolos, que adornan con plumas de pavo real. Adoran el Sol y esperan el advenimiento del hombre-luz. Pero él no es Cristo. ${ }^{19}$ (Werfel, Juárez y Maximiliano 11)

Este diálogo nos habla del imaginario que Werfel tenía sobre los indios en América del Norte, los indios de México y los mexicanos en general. Si bien habla de la mezcla entre indígenas y blancos, también añade una descripción de raras y antiguas costumbres preservadas en lo profundo de las montañas mexicanas; que concuerda con el exotismo con que los europeos veían a América, mismo que caracterizó al romanticismo. Alejado ya por varias décadas de esta tendencia, el praguense no abunda más en el tema.

En cambio, Werfel abre en varias ocasiones la discusión sobre el modo de ser de los austriacos y establece una relación de ellos con la culpa; no obstante, esto también fue eliminado por la traductora. Así como la presencia o mención del niño Iturbide que fue también reducida en la versión de Langner. Más allá de las pérdidas, Langner incluso reescribió la historia del origen de Benito Juárez eliminando las partes en las que se hablaba de los malos tratos de su familia y de su llegada a la ciudad sin saber hablar español.

18 "Sagt mir lieber Mann! Eure indianer gleichen unseren nordischen Rothäuten nicht. Sie sind ja hier das Volk, die große Masse. Sie versmischen sich mit den Weißen, leben in den Städten und tragen unsere Kleidung. Aber gibt es nicht Stämme die ihre Religion und Sitte bewahrt haben?" (Werfel, Juarez und Maximilian 14-15).

19 "Oh, Señor! Viele hunderttausend in der Sierra Madre, in der Sierra Leone, in allen Gebirgen! Sie verschmähen die Sakramente, sie haben ihre Altäre, ihre Zauber, ihre Tempeltrommel, ihre Götzen, die sie mit den Federn des Truthahns schmücken. Sie beten die Sonne an und warten auf den lichten Mann, der da kommen wird. Dies aber ist nicht Christus" (Werfel, Juarez und Maximilian 15). 


\section{Los problemas de la traducción y los contextos culturales}

El modelo de comunicación de Sonesson identifica tres dominios a los que se enfrenta el individuo en la sociedad: la Ego-cultura o dominio del sujeto, la Alter-cultura o dominio del no-sujeto y la Alius-cultura el dominio de la no-persona, que desde la perspectiva del Ego no existe (Sonesson 174). De esta forma, la traducción ocurre generalmente entre la Ego-cultura y la Alter-cultura, y sólo en momentos tales como la Conquista, se ha llegado a la comunicación con la Alius-cultura, es decir lo desconocido. El conocimiento de los contenidos de ambas culturas en tiempos y espacios específicos se vuelve más complejo cuando lo que se quiere transmitir es tan poco conocido que se acerca a ser Alius-cultura.

En este punto, cabe recordar que Juarez und Maximilian es una obra austriaca, específicamente vienesa, correspondiente al periodo de entreguerras, por lo que como es de esperarse, algunos de sus términos e ideas no son comprensibles fuera de dicho contexto. Es importante considerar que, por su propia dinámica, el teatro vienés estaba estrechamente ligado al lenguaje popular ${ }^{20}$ y fuertemente marcado por la política local (Pyrah). En ese sentido, la traducción de algunos de los diálogos de la obra resulta problemática o pueden parecer inadecuados a ojos de los traductores, que en ocasiones prefieren eliminarlos.

Como resultado del trabajo entre la Ego-cultura y la Alter-cultura, dentro de la labor del traductor, es frecuente encontrar problemas de diacronía, diatopía o diacultura. Esto es, problemas relacionados con los cambios del lenguaje ocurridos por el paso del tiempo (diacronía); aquellas diferencias existentes en las palabras utilizadas en lugares distintos, pero del mismo idioma (diatopía); y la falta de correspondencia entre palabras o significados en dos culturas distintas, a saber, entre las que se realiza la traducción (diacultura) (Albaladejo Martínez 31-36). Se puede decir que, el alemán utilizado por Werfel en su drama corresponde al estándar del idioma, aunque con algunas formas anticuadas como el uso constante de gerundios. Sin embargo, la obra intenta acercarse a la cultura y el idioma de México, el lugar en donde se desarrolla la acción. Además, las traducciones atraviesan varios contextos, el neoyorkino, el mexicano y el español, e incluso el argentino, por lo que se trata de un buen ejemplo de los problemas que la diacultura puede presentar al traductor de una obra.

A nivel sociocultural, el texto se mantiene en un lenguaje refinado, adecuado para la corte imperial, presentando una variación significativa únicamente en los diálogos que Maximiliano mantiene con Yatipan y Polifemo, soldados mexicanos. Es en ese contexto donde se puede apreciar una marcación lingüística, con la que Werfel busca enfatizar la escasa educación de los soldados mexicanos, y su diferencia con los soldados austrohúngaros, representados por el cabo Wimberger. En su conversación, el soldado Yatipán cuestiona la presencia del cabo austrohúngaro en México, mientras pasa del tono burlón a la confianza y el tuteo con su superior a quien llama "hermano": No obstante, no podría decirse que se trate de un texto marcado, es decir, una obra que recurra a la marcación intralingüística
(mediante la variación diastópica, diastrática o diafásica) de forma preponderante (Albaladejo Martínez 27-28). Salvo
algunas excepciones que se señalarán más delante. 
Yatipán: ¡Ayayay! Eres un gran señor ¿Es que allá también has estado con el pronunciamiento del emperador? [...]

Yatipán: ¿Ves, Cabo? Yo era así de chiquito y vienen los de la leva: "Muchacho ven, hay pronunciamiento". La primera revolución me pagaba tres centavos al día. La segunda, medio año más tarde, cinco centavos. Hermano, estuve en diecisiete pronunciamientos, blancos y rojos, ninguno me dio más de diez centavos... Y tú, ¿qué sacaste de la revolución? ${ }^{21}$ (Werfel, Juárez y Maximiliano 92).

Asimismo, para acercarse al contexto mexicano del Segundo Imperio, Werfel utiliza algunas palabras en español tales como "Señorita" (Werfel, Juarez und Maximilian 136), nombre con el que se refiere Wimberger a su novia. Pero, al mismo tiempo, utiliza la versión germanizada del nombre Tomás Mejía: Thomas Meja. Por su parte, Enrique Jiménez hizo su traducción manteniendo incluso el error en el nombre de Yatipan, ${ }^{22}$ que en las traducciones respectivas de Langner y Jiménez aparecen como Yapitan a lo largo de todo el texto.

Algunos de los términos usados en el drama cambian de significado. El adjetivo con el que escribe Werfel, en voz del corresponsal Clark, a Agustín de Iturbide es "Parvenu" (Werfel, Juarez und Maximilian 12), que puede usarse para referir a los nuevos ricos con una connotación negativa, es decir, como advenedizos. Langner utilizó el mismo término que también se utiliza en el inglés, "parvenu" (Werfel, Juarez and Maximilian 4), mientras que Jiménez lo traduce como "aventurero" (Werfel, Juárez y Maximiliano. Historia dramática 16). Con esto Jiménez atenúa la opinión negativa sobre Iturbide.

Centrémonos ahora en la versión al español que realizaron Lifezis y Martín, en 1946, y que fue publicada en México en 2002. Dicha obra se ubica ya dentro del proceso de profesionalización que se vivía en Argentina en este periodo, en el que se le considera "la meca editorial de América Latina" (Willson 30). ${ }^{23}$ Si bien las traductoras no se formaron aun en una escuela especializada, al menos Lifezis sí contaba con una carrera prolongada en el ámbito editorial y ambas continuarían dedicadas a la traducción de textos literarios durante varias décadas. Su colaboración resuelve, además, al menos en parte, uno de los principales problemas al que se enfrenta el traductor: el conocimiento cultural. En la dupla, Lifezis tiene el dominio de la cultura austriaca (Ego-cultura austriaca y Alter-cultura hispana), mientras Martín posee el dominio del español (Ego-cultura hispana y Alter-cultura austriaca). No obstante, debido a

${ }^{21}$ "Yatipan: Ayaya! Du bist ein großer Herr! Hast Du drüben schon für den Kaiser pronuntschiamentiert? [...] Yatipan: ¡Weißt Korporal! Ich war noch so klein! ¡Da kommen die Kerle von der Soldatenpresse! ‘Bub! Pronuntschiamentier Dich! Wir machen Revolution!' Die erste Revolution hat mir drei Centavos im Tag gezahlt! Die zweite, ein halbes Jahr später, fünf Centavos! Bruder, ich hab mich für siebzehn Revolutionen, weiße und rote, pronuntschiämentiert. Aber mehr als zehn Centavos hat keine gegeben ... Und Du, was hast Du von der Revolution gehabt?" (Werfel, Juarez und Maximilian 136137).

22 Se invierte el orden de las consonantes t y p, de forma que Yatipan se convierte en Yapitan. Mientras que Yapitan no tiene significado alguno, el nombre Yatipan significa "lugar de guerra" en náhuatl y corresponde con un poblado del estado de Hidalgo, en México (Peñafiel 322).

23 Entre los factores que hicieron posible este esplendor, Patricia Willson señala el eclipse de la editorial española debido a la guerra — hecho que igualmente está ligado al asentamiento de impresores españoles en Argentina-, la previa profesionalización de los escritores argentinos y la conformación de una población lectora importante en las ciudades. Con todo, en la década de 1930 la mayoría de los traductores eran españoles avecindados y es hasta años después que empiezan a aparecer traductores argentinos en las portadas (Willson 60, 230). 
las características del texto, se observa que el desconocimiento de la historia mexicana — en algunos aspectos Alius-cultura para ambas-, lleva a Lifezis y Martín a confundir algunas cosas. Por ejemplo, cuando se menciona a los "chinacos" — guerrilleros republicanos - , y los llaman "chinangos" (Werfel, Juárez y Maximiliano 93). Asimismo, en el elogio antes mencionado hacia Díaz, traducen: "Victorias contra Bazaine, Trujeque, Ganz, luminarias todos ellos de la escuela de guerra. Y sin embargo tú eres juarista y de las sutilezas de la estrategia entiendes tanto como del arte de hacer sonetos" (Werfel, Juárez y Maximiliano 64).

El cambio en el sentido es notorio. Mientras en el texto fuente, Werfel habla de lo polifacético de Díaz, Lifezis y Martín sugieren una incompatibilidad entre las victorias militares del general y la estrategia fina, que le estaría negada a los juaristas al igual que la poesía. Al parecer consideraron imposible que Díaz hubiera estudiado leyes o supiera de sonetos.

En contraparte, una de las ideas complejas que las traductoras debieron superar en la traducción es la de "k. u k.", un concepto conocido para los austrohúngaros, pero completamente extraño para el resto del mundo —una de las menciones al carácter austrohúngaro que Langner omitió - . Cuando, en su desesperación, la princesa de Salm critica al embajador austriaco por negarse a firmar una letra de cambio:

Da handelt es sich um einen lächerlichen Wechsel, den der österreichische Gesandte kontrasignieren soll, weil kein Geld da ist. Aber er weigert sich, der Eitelkeitskadaver, der bürokratische. Er könnte die "k. u. k. Gesandtschaft kompromittieren”. Männer??? Ha! Verprügelte Internatsknaben sind das, Jesuitenopfer, lasterhafte! Die Flucht ist zum Teufel gegangen [...]. ${ }^{24}$ (Werfel, Juarez und Maximilian 166)

No se trataba más que de un ridículo pagaré que tendría que firmar el embajador de Austria, porque faltaba dinero. Pero ese cadáver burócrata rehusó firmarlo. Teme comprometer a la Embajada Imperial y Real. ¡Hombres! ¡Ja...! ¡Niños de internado acobardados a palos, víctimas de los maestros! Así el diablo desbarató la huida... (Werfel, Juárez y Maximiliano 111)

La princesa hace primero una crítica a la burocracia austriaca, un tema que otros escritores como Franz Kafka (1883-1924), Ernst Lothar (1890-1974) y Robert Musil (1880-1942), habían tratado anteriormente debido a su importancia dentro del Imperio (Islas Flores 15-16). Aquí la k. y k. abrevian Kaiserlich (Imperial) y Königlich (Real). En El hombre sin atributos, Robert Musil explica el significado que esto tenía en Austro-Hungría, a la que llamó en su novela precisamente Kakania:

Todo objeto, institución y persona llevaba algunos de los signos k.k. o bien k.u.k., pero se necesitaba una ciencia especial para poder adivinar a qué clase, corporación o persona correspondía uno u otro título... Según la Constitución, el Estado era liberal, pero tenía un gobierno clerical. (Musil 36)

24 "Era un ridículo pagaré que el embajador de Austria debía firmar porque no tenemos dinero. Pero él se negó, el cadáver de la vanidad, el burócrata. Podría ser la 'K y K. de la legación comprometida'. ¿¿Hombres?? ija! Son muchachos de internado, jesuitas, viciosos, la fuga se fue al infierno...” (Traducción propia). 
En el mismo párrafo, se nota la adecuación de los términos "Jesuitenopfer" (víctimas de los jesuitas) y "lasterhafte" (viciosos), los cuales las traductoras decidieron eliminar probablemente para no hacer referencia directa a dicha institución religiosa y centrarse en la idea de control. En su lugar escribieron "víctimas de los maestros", con lo que se mantiene el sentido del párrafo para decir "casi lo mismo", tras realizar el necesario proceso de negociación.

\section{Conclusiones}

La traducción es una labor compleja que, aunque ha existido desde que existen diferentes lenguas, no había sido objeto de tanta atención y cuidado como en el último siglo. A partir de la segunda mitad del siglo xx, la profesionalización de la traducción, con la aparición de escuelas y personas dedicadas exclusivamente a esta actividad, ha dado un marco mucho más sólido a nivel teórico y técnico, que permite un nivel de exigencia alto en dicha labor. Las traducciones analizadas en este trabajo pertenecen a un periodo de transición hacia dicha profesionalización, dando como resultado una obra, la de Langner y, por consecuencia, Jiménez. Un trabajo tan divergente dentro de un esquema editorial más profesional sería criticado como traducción, o al menos etiquetado como "versión de", o "basado en", epígrafes que advierten sobre la distancia entre el original y el texto presentado. Nada de esto consideraron los editores, que en buena medida eran los mismos traductores, sus motivos los desconocemos, pero pudo deberse a su poca experiencia en la materia. En contraste, el texto traducido por Martín y Reney es el resultado de un trabajo de traducción profesional, cuyos problemas menores se deben al desconocimiento del tema tratado en la obra. Con esto, se demuestra la importancia del conocimiento cultural, no solo de la cultura de partida del texto y la cultura de llegada, sino de la materia que se expresa en la obra, en este caso, la historia de México.

Asimismo, el trabajo hecho por Martín y Lifezis es un ejemplo del buen resultado del trabajo en pares para disminuir los problemas ocasionados por el doble proceso de traducción. Lifezis como nativa de la cultura de partida establece el diálogo con Martín, quien es parte de la cultura de llegada. Los problemas encontrados se deben precisamente a que, finalmente, Martín, pese a ser una hablante nativa del español, no conocía el contexto cultural mexicano en el que se desarrolla la obra, por lo que no comparte todos sus códigos. Este problema es resuelto en muchas ocasiones con una investigación del tema, misma que, debido a la época y ubicación de las traductoras, pudo ser complicada.

Los aproximadamente 7000 kilómetros de distancia se habían vuelto aún más grandes a partir de la Revolución mexicana iniciada en 1910. Esta guerra civil significó un cambio en lo político y cultural del país, principalmente por sus demandas de reparto agrario, derechos laborales y sociales, lo que no era visto con buenos ojos por los ricos hacendados argentinos. El representante diplomático de México en Argentina, en 1921, Antonio Mediz Bolio, le comentaría a Alfonso Reyes: "Nos ignoran en absoluto. Conocen y con entusiasmo a algunos de nuestros hombres [...], pero no tienen idea de México" (Yankelevich 94). Aunque la embajada de México en Argentina se abre en 1927, con Alfonso Reyes como primer embajador, los intercambios fueron escasos. Las relaciones comerciales eran tan mínimas que no se contaba con una ruta marítima directa que uniera a ambos países, y los dos proyectos de establecerla 
antes de la Segunda Guerra Mundial fracasaron (Zuleta Miranda; Yankelevich). No es extraño, por tanto, que Martín y Lifezis tuvieran pocos conocimientos de la historia de México.

Finalmente, este trabajo no puede ser una exposición exhaustiva de las diferencias y cambios ocurridos en la traducción, pero sí demuestra las divergencias que pueden darse en el proceso de traducción. En el caso de Juarez und Maximilian, se evidencia la importancia sustantiva del contexto y la autoría, es decir, los factores culturales tanto del texto fuente (Ego-cultura) como de los textos meta (Alter-cultura) en el proceso de la traducción.

\section{Referencias}

Albaladejo Martínez, Juan Antonio. La literatura marcada: problemas de traducción y recepción ejemplificados a través del teatro popular vienés. Soria, Vertere, Monográficos de la Revista Hermeneus 14, 2012.

Bastin, Georges. "Por una historia de la traducción en Hispanoamérica". Íkala. Revista de lenguaje y cultura, vol. 8, núm. 14 ene-dic. (2003): 193-217. Web 29 Oct. 2021. https://www.redalyc.org/pdf/2550/255026028009.pdf

Cagiao Vila, María del Pilar. "Género y emigración: las mujeres inmigrantes gallegas en la Argentina”. La Galicia Austral. La inmigración gallega en la Argentina. Ed. Xosé Núñez Seixas. Buenos Aires, Editorial Biblos, 2001, pp. 107-138.

Dusi, Nicola Maria. "Intersemiotic translation: Theories, problems, analysis". Semiotica. Journal of the International Association for Semiotic Studies, núm. 206 jul. (2015):181-205. Web 14 May. 2021. https://philpapers.org/rec/DUSITT

Eco, Umberto. Experience in Translation. Trad. Alastair McEwen. Buffalo, University of Toronto Press, 2001.

Eco, Umberto. Decir casi lo mismo. Experiencias de traducción. Trad. Helena Lozano Miralles. México, Lumen, 2008.

Gallego Roca, Miguel. "De las vanguardias a la Guerra Civill". Historia de la traducción en España. Eds. Francisco Lafarga y Luis Pegenaute. Salamanca, Editorial Ambos Mundos, 2004, pp. 479-526.

Garner, Paul. Porfirio Díaz: entre el mito y la historia. Trad. Luis Pérez. México, Crítica, 2015. 
Islas Flores, Mario César. La escritura imbricada de Robert Musil: Historia politica y mística en El hombre sin atributos. Tesis doctoral Universidad Autónoma Metropolitana-Unidad Azcapotzalco, México, 2015.

Jakobson, Roman. "On linguistic aspects of translation”. On Translation. Ed. Reuben Brower. Cambridge, Harvard University Press, 1959, pp. 232-239.

Milhaud, Darius. Maximilien. Opéra historique en trois Actes et neuf Tableaux. Livret de R. S. Hoffmann d'après “Juarez et Maximilien". Drame de Franz Werfel. Adaptation Française d'Armand Lunel. Viena, Leipzig Universal-Edition, 1931.

Morales Zea, María del Sol. "Juárez y Maximiliano: cruces entre la literatura y el cine 19241933”. Revista Valenciana, núm. 27 ene-jun. (2021): 119-145. Web 29 Oct. 2021. https://doi.org/10.15174/rv.v13i27.51

Musil, Robert. El hombre sin atributos. Trad. José M. Sáenz. Barcelona, Seix Barral, 2004.

Peñafiel, Antonio. Nomenclatura geográfica de México, vol. 2. México, Oficina Tipográfica de la Secretaría de Fomento, 1897.

Peredo, Roberto. "Enrique Jiménez Domínguez". Diccionario enciclopédico veracruzano, Universidad Veracruzana. Web 29 Jun. 2021. https://sapp.uv.mx/egv/about.aspx

Pérez Martínez, Herón. “Alfonso Reyes y la traducción en México”. Relaciones. Estudios de Historia y Sociedad, vol.14, núm. 56 (1993): 27-74.

Pyrah, Robert. The Burgtheater and Austrian Identity. Theater and cultural politics in Vienna 1918-1938. Londres, Routledge, 2007.

Sonesson, Göran. "La traducción como doble acto de comunicación. Entre semiótica cognoscitiva y semiótica de la cultura. Parte I. De la comunicación a la traducción". Interpretatio. Revista de Hermeneútica, vol. 3, núm. 2 (2018-2019): 159-187. Web 29 Oct. 2021. https://revistas-filologicas.unam.mx/interpretatio/index.php/in/article/ view/105

Vázquez Vela, Gonzalo. Memoria de la Secretaría de Educación Pública, septiembre 1936-agosto 1937, presentada al H. Congreso de la Unión. Tomo 1, segunda parte, México, D.A. P.P., 1937.

Vega Cernuda, Miguel Ángel. "De la Guerra Civil al pasado inmediato". Historia de la traducción en España. Eds. Francisco Lafarga y Luis Pegenaute, Salamanca, Editorial Ambos Mundos, 2004, pp. 527-578. 
Werfel, Franz. Juarez und Maximilian. Dramatische historie in 3 phasen und 13 bildern, Berlín, Paul Zsolnay, 1924.

Werfel, Franz. Juarez and Maximilian. A dramatic history in three phases and thirteen pictures. Trad. Ruth Langner. Nueva York, The Theatre Guild Inc., 1926.

Werfel, Franz. Juárez y Maximiliano. Historia dramática en tres actos y trece cuadros. Trad. Enrique Jiménez Domínguez. México, Ediciones de "La razón” S. A., 1931.

Werfel, Franz. Juárez y Maximiliano. Trads. Elvira Martín y Annie Reney. México, Factoría Ediciones, 2002.

Willson, Patricia. La constelación del Sur. Traductores y traducciones en la literatura argentina del siglo XX. Buenos Aires, Siglo xxi Editores, 2004.

Yankelevich, Pablo. "México-Argentina. Itinerario de una relación 1910-1930". Tzintzun. Revista de Estudios Históricos, núm. 45 ene-jun. (2007): 83-104. Web 29 Oct. 2021. https://www.redalyc.org/pdf/898/89804505.pdf

Zuleta Miranda, María Cecilia. “Alfonso Reyes y las relaciones México-Argentina: proyectos y realidades, 1926-1936”. Historia Mexicana, vol. 45, núm. 4 (1996), pp. 867905. Web 29 Oct. 2021. https://www.jstor.org/stable/25139023 